\title{
captação e abastecimento de água na são paulo de ontem e de hoje: continuidades e descontinuidades ${ }^{\star}$
}

\section{water collection and supply in são paulo city, past and present: continuities and discontinuities}

\author{
Fábio Alexandre dos Santos $\star \star$ \\ Universidade Federal de São Paulo, Campus Osasco, Osasco, São Paulo, Brasil
}

RESUMO

Este artigo se propõe a discutir o tema da captação de água destinada ao abastecimento da população da cidade de São Paulo e da Região Metropolitana de São Paulo. Sob a responsabilidade do governo do estado de São Paulo desde 1892, o artigo foca especialmente a continuidade de padrões de captação que foram reproduzidos ao longo do século XX, em paralelo às dinâmicas nas transformações urbanas e econômicas que impuseram descontinuidades nos aspectos ligados à gestão da empresa encarregada da captação e distribuição e no aumento da demanda de água. Em meio a essas continuidades e descontinuidades, os custos sociais da falta d'água revelados pelo crescente aumento na sua demanda, em contraposição à ineficiente oferta, reproduzem desigualdades já instauradas na região, resultado de uma urbanização privada e desigual.

Palavras-chave: São Paulo. Captação de água. Saneamento. Urbanização. Desigualdades.

\begin{abstract}
This article seeks to discuss the water collection with the aim of sourcing population of São Paulo city and of Metropolitan Region of São Paulo, under responsibility São Paulo Government State since 1892, highlighting the remained standard of collection that were reproduced along twentieth Century, at the same time as urban and economics transformations forced to discontinue the management aspects of the company responsible for collecting and distributing water and increased the demand. In the midst of this continuity and discontinuity arena, the social costs of water shortage that come up with the growing water demand and, on the other hand, its inefficient offer, reproduce inequalities that can be already found on the region, result of private and irregular urbanization that, consequently, caused the water degradation and justify its collection away from the city.
\end{abstract}

Keywords: São Paulo. Capture of water. Sanitation. Urbanization. Inequalities.

* Este artigo amplia as questões apresentadas no $2^{\circ}$ Simpósio Internacional de História Ambiental e Migrações, em Florianópolis (Santa Catarina) e no III Congresso Latinoamericano de História Econômica, em Bariloche (Argentina), ambos realizados no segundo semestre de 2012.

Submetido: 7 de abril de 2013; aceito: 11 de maio de 2013.

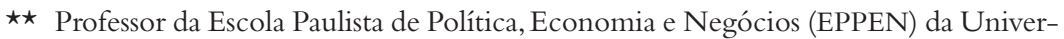
sidade Federal de São Paulo, Campus Osasco, e-mail: fa.santos@unifesp.br 


\section{Introdução}

O povoamento inicial que resultaria na atual Região Metropolitana de São Paulo (RMSP) foi gerado no início do século XVI sobre uma colina numa área cercada por rios e córregos, os quais abasteciam seus habitantes e os guardavam de possíveis ataques indígenas, rodeada pelo ribeirão Anhangabaú, pelo rio Tamanduateí e suas várzeas. Na atualidade, essa região abriga o Centro Velho de São Paulo, no entorno do Pátio do Colégio, próximo ao rio Anhangabaú - que corre sob o asfalto e o concreto das construções e túneis da região, escondido dos olhares. Já o rio Tamanduateí, cujas águas percorriam um sinuoso caminho até desaguar no rio Tietê, teve seu curso natural alterado e transposto, em cuja área central, hoje, se encontra a famosa rua de comércio popular da capital paulista, a 25 de Março.

Essas referências entre passado e presente são simbólicas, pois demonstram como as águas que atravessavam a região central foram as primeiras, mas não as únicas a sofrerem as diversas "interferências" realizadas pelo homem no afã de sobrepor barreiras, ocupar espaços, afastar o indesejado etc ${ }^{1}$. Nesse quadro, problemas, desafios e contradições relacionados à água adquiriram conotações que muito impactaram e ainda impactam a vida da população. Tal processo, por sua vez, resultou em consequências nefastas ao abastecimento de água à população, pois, mesmo estando situada sobre uma importante bacia hidrográfica com abundância deste importante bem natural, levou o poder público a instaurar um padrão de captação de água em locais distantes da cidade de São Paulo, com custos crescentes, cuja lógica se reproduz na atualidade ${ }^{2}$.

1 O que se estabeleceu foi uma das dimensões da relação homem e natureza, em que a segunda deve ser tratada como algo distinto do primeiro, mesmo sendo este parte daquela. Porém, caso o homem deixe de existir, a natureza continuaria a existir. O que se coloca é que a natureza é uma criação cultural, diretamente ligada às representações das mentes humanas e de seus respectivos grupos e significações (WORSTEN, 1991: 210).

2 O que se propõe, portanto, é uma abordagem da relação entre sociedade e natureza, na qual esta última deve ser compreendida como parte do processo social, nas suas dimensões fisica e material, na medida em que possui valores e significados pela sua presença na vida das pessoas, pois o ambiente é uma construção social (MARTINEZ, 2006: 21). Não é à toa que toda transformação em qualquer área resulta em 
$\mathrm{Na}$ intersecção das relações e interesses dos homens com o ambiente, as águas passaram por transfigurações em seus aspectos físicos, naturais, tornando-se cada vez mais degradadas em razão de se transformarem gradativamente em um "veículo" de afastamento do indesejado (os resíduos); da mesma forma, também passou por transformações em seus aspectos culturais - transfigurando-se, assim, em obstáculo à ocupação do espaço (para expansão do mercado imobiliário), e, ainda, em fonte para geração de energia (SANTOS, 2011: 293 e segs.).

O rio Tamanduateí, por exemplo, cujo percurso foi primordial na delimitação inicial do núcleo urbano e seu processo irradiador ulterior, passou por três intervenções até resultar no seu curso atual. Da mesma forma, os rios Pinheiros e Tietê, de importância ímpar na hidrografia da região, também sofreram com intervenções, retificações, supressão de suas áreas de várzeas e degradação. Igualmente impactante, dezenas de outros rios e córregos também foram canalizados e/ ou entubados na cidade, sobre os quais, atualmente, há avenidas e ruas, o que contribui sobremaneira para o fenômeno das inundações na cidade de São Paulo, como o caso do ribeirão Anhangabaú. Dessa forma, todos esses cursos d'água, em especial os rios Tietê, Pinheiros e Tamanduateí, como são responsáveis pela macrodrenagem da bacia do Alto Tietê, acabaram impactando, de alguma maneira, a hidrografia da região, na medida em que foram objetos das intervenções urbanas.

Essas intervenções e os "melhoramentos urbanos" levados adiante pelo poder público justificavam-se à medida que a cidade de São Paulo passava a colher os frutos da riqueza advinda do complexo cafeeiro, simbolizado especialmente pela inauguração das primeiras linhas férreas ligando o interior produtor ao porto exportador, Santos, em cujo caminho estava a capital paulista, a partir da década de 1860. Por isso, se fazia imperioso dotar a cidade de equipamentos urbanos que representassem uma capital moderna e civilizada, com serviços públicos condizentes a esse status, dentre os quais estavam o abastecimento de água, a coleta de esgotos, o transporte urbano etc. Em conjunto, tais medidas deveriam dar conta da supressão da sujeira, fosse ela humana, fisica,

reformulações, rearranjos ou perdas de representações para a sociedade que nela vive e em suas respectivas manifestações culturais. O homem é parte dessa natureza, e, como com ela interage, pode, inclusive, provocar intervenções inadequadas (MASSEI, 2007: 228-229). 
palpável ou não palpável, estabelecida nos hábitos, nas práticas e nas concepções, sem os quais poderiam fazer emergir subversão, vadiagem, promiscuidade e oposição (DOUGLAS, 1966: cap. II) ${ }^{3}$.

Sob esse quadro, o serviço de abastecimento de água foi encampado pelo governo do Estado de São Paulo em 1892, tendo sido o primeiro serviço "estatizado" pelo governo num momento de redefinição política - a instauração da República - sob a justificativa de dar conta do acréscimo de demanda à luz do aumento da riqueza advinda do complexo cafeeiro (CANO, 1998: 32 e segs.) que, juntamente com o Serviço Sanitário, deveriam cuidar da "saúde" do espaço físico e da mão de obra que se estabelecia especialmente na cidade de São Paulo.

É sobre este serviço, com destaque para a captação da água executada pelas diferentes empresas ligadas ao governo do Estado de São Paulo ao longo do período em questão, que esta reflexão se debruça, colocando inquietações para futuros aprofundamentos.

\section{República e urbanização}

A Proclamação da República, em 1889, foi um momento de inflexão na história política brasileira, com a substituição da Monarquia pela República, e também um momento de alterações no funcionamento da estrutura econômico-financeira do Estado Nacional, ao proporcionar maior capacidade de ação do poder público estadual sobre seus estados, o que se refletiu em seus processos urbanos, que, nos casos dos estados em melhores condições econômicas naquele momento se revelaram bastante propícios.

No que se refere a São Paulo, irradiaram-se, a partir da última década do século XIX, importantes medidas econômicas e intervenções urbanas que ecoaram em direta correlação aos interesses dos homens alocados no poder, os quais representavam as preocupações imediatas do complexo cafeeiro e simbolizavam toda sorte de mudanças em curso no então estado, cujos ganhos foram sentidos na cidade de São Paulo.

3 Segundo a autora, no âmbito da noção da pureza e do perigo, há que se considerar que estas concepções são construídas historicamente segundo as diferentes realidades culturais e históricas, diretamente relacionadas aos interesses dos grupos dominantes. 
O ponto de emanação das mudanças políticas e econômicas se deu com a instauração de uma esfera federativa no plano fiscal e no plano político. No primeiro caso, foi a efetivação de os estados gerenciarem exclusivamente os impostos sobre as exportações (antes partilhado com o governo Imperial). No segundo caso, foi a constituição de uma esfera política eletiva (os governadores), que permitiu às oligarquias regionais se consolidarem no poder com suas estruturas sem as ameaças de possíveis "derrubadas", típicas do período imperial. Esses fatores conferiram às capitais dos estados os elementos necessários para a consolidação de espaços político-institucionais em ascensão, assim como de núcleos de expressão política e cultural de suas oligarquias (COSTA, 1998;141-173).

Dada a inserção de São Paulo no circuito comercial internacional por meio do complexo econômico cafeeiro, seu diferencial foi deter recursos, naquele momento, para que seus legisladores investissem e legislassem em causa própria, segundo seus interesses políticos e econômicos (já que representavam, na sua grande maioria, homens ligados ao complexo cafeeiro).Ademais, com as mudanças político-econômicas, os estados também estavam autorizados, a partir de então, a contrair empréstimos externos.

Segundo Nozoe (1984), essas descentralizações modificaram as condições econômico-financeiras de São Paulo, gerando um "extraordinário aumento da receita" no exercício de 1892, ante a receita anterior à reforma; assim, “em 1890-1891 a receita foi de 9.100 contos de réis e, em 1892 chegou a 388.100 contos de réis" (NOZOE, 1984: 18). Acrescido a esta receita, e igualmente relevante aos cofres do estado, o café encontrava-se em alta naqueles anos, em vendas e em cotação, alcançado no exercício de 1892 uma quantidade exportada de 245.456.719 quilos (kg), diferente dos $137.898 .061 \mathrm{~kg}$ exportados em 1888-1890.Já o valor médio do quilo saltou de \$586 em 1889-1890 para 1\$026 em 1892.

Esses recursos permitem compreender como os homens instalados no poder os utilizaram no sentido de criar uma série de regulamentações e serviços que atenderam aos seus interesses. Entre eles, estavam àqueles ligados à realidade urbana e às demandas que cresciam naquele momento, os quais deveriam representar, no espaço físico, a riqueza que a atingia, simbolizada e justificada pela modernização ${ }^{4}$ requerida para a cidade

4 Modernização no sentido de abarcar o conjunto das cidades, tanto em suas expressões materiais, através dos níveis e estruturas políticas, econômicas e sociais, quanto 
desejada - civilizada ${ }^{5}$ - , como a encampação da Cia. Cantareira pelo governo do Estado de São Paulo, que será tratada com mais detalhes adiante.

Outras duas medidas criadas em 1892 foram a criação do Serviço Sanitário e a imigração subsidiada. Quanto à primeira, além dos aspectos financeiros necessários e disponíveis naquele momento, sua estruturação foi possível em razão dos fatores decorrentes da descentralização das organizações sanitárias determinadas pelo Decreto Federal de 30 de dezembro de $1891^{6}$.

As primeiras ações sanitárias do período republicano em São Paulo remontam à Lei $n^{\circ} 43$, de junho de 1892, cuja origem estava conjugada à tríade urbanização-economia-salubridade, por isso, sintomaticamente, seu foco inicial de intervenções foi direcionado ao meio físico, à cidade, locus das relações sociais e econômicas.

A segunda medida foi a política de imigração de massa, com o objetivo de atender aos interesses dos cafeicultores preocupados com a possível escassez de mão de obra nas lavouras, por meio da qual o estado arcava com as despesas de viagens daqueles que desejassem migrar para São Paulo com destino às lavouras de café. Mas os resultados re-

espirituais, marcada pela espiritualidade daqueles que se dedicavam à vida artística e intelectual autônoma, incluindo os chamados "modernistas". Enquanto esses níveis aparecessem separadamente, se esvaziaria a possibilidade de apreensão da conjuntura da vida moderna; por isso, deveria ser essencial "a fusão de suas forças materiais e espirituais, a interdependência entre indivíduo e o ambiente moderno" (BERMAN, 1986: 129).

5 A ideia e o conceito de civilização remonta a um período anterior à própria Revolução Industrial, momento em que os Estados Absolutistas atravessavam sua fase de consolidação e traziam em si mudanças nas noções de como se portar em público, comer, falar etc. Ao tratar do processo civilizador na corte francesa, Norbert Elias ressalta que tal processo implica um "contra conceito geral a outro estágio da sociedade, a barbárie. (...) A civilização não é apenas um estado, é um processo que deve prosseguir (...) Ela absorve muito do que sempre fez a corte acreditar ser em comparação com os que vivem de maneira mais simples, mais incivilizada ou mais bárbara - um tipo mais elevado de sociedade: a ideia de um padrão de moral e costumes, isto é, tato social, consideração pelo próximo, e numerosos complexos semelhantes" (ELIAS, 1994: 62).

6 A constituição das práticas sanitárias e dos serviços de saúde não ocorreu de forma uniforme no território brasileiro; ao contrário, foi marcada por diferenças regionais em termos políticos e econômicos, característica da chamada Primeira República. Somente o Rio de Janeiro, em função de seu status de capital federal, se compara aos serviços instaurados em São Paulo (MERHY, 1987: 49-50). 
percutiram largamente na capital do estado nos anos seguintes (HOLLOWAY, 1984: 68 e 84)7. Com essa política, além de outros fatores, é claro, a população da cidade de São Paulo saltou, em 1890, de 64.934 habitantes para 239.820, dez anos depois, em 1900; já em 1920, passou a abrigar 579.033 habitantes (SANTOS, 1994: 137).

A terceira medida implementada pelo governo do estado de São Paulo foi a encampação dos serviços de água e esgoto, cuja oferta não atendia à crescente demanda, e menos ainda com a qualidade necessária para o consumo humano.

As águas oferecidas à população, oriundas dos chafarizes ou dos rios e córregos, já suscitavam problemas pelo processo de desmantelamento dos primeiros, pela degradação dos segundos, e até pela sua transformação em mercadoria, a partir da concessão dos serviços de abastecimento de água e coleta de esgotos à Cia. Cantareira, em 1877, empresa privada que tinha como objetivo melhorar os serviços. Inclusive, a razão do desmanche dos chafarizes era justamente não ofertá-la mais "gratuitamente", obrigando a população a "pagar" por ela ${ }^{8}$.

De qualquer forma, no início da última década do século XIX, os serviços da Cia. Cantareira não atendiam à demanda, devido ao aumento da população que crescia motivada pela imigração e pelo aparecimento de pequenas indústrias que demandavam cada vez mais infraestrutura e trabalhadores (PASQUA, 1998: 34) ${ }^{9}$. E foi esta a justificativa para a encampação pelo governo do estado, sob o argumento de melhorar a oferta.Tal fato se concretizou por meio da Lei número 62, de 17 de agosto de 1892 , conforme autorização que rezava o artigo $4^{\circ}$ da mesma lei, expedido pelo Decreto número 140, de 26 de dezembro de 1892, assinado por Bernardino de Campos e referendado pelo Dr. Jorge Tibiriçá, secretário da agricultura, que concedeu e liberou junto ao Te-

7 Há que se considerar, evidentemente, os fatores de expulsão nos países de origem daqueles que migraram que, devido aos limites aqui impostos, não serão discutidos.

8 Sobre os serviços de abastecimento de água no século XIX, consultar especialmente SANT'ANNA (2004; 2007).

9 Há divergências quanto à eficácia dos serviços de abastecimento de água oferecidos à população no final do século XIX em São Paulo. Para Singer (1977: 39), foi “o melhor serviço de águas e esgotos do Brasil na época”. Já para Bruno (1991: 649 e segs.) os serviços de abastecimento de água em São Paulo nunca chegaram a ser satisfatórios, principalmente na época em que as águas eram oferecidas unicamente através dos chafarizes. 
souro do Estado um crédito de 6.829:546\$663, cujo montante foi utilizado para o pagamento à Cia. Cantareira e Esgotos da Capital (MARTINS, 2003: 413). Com a encampação, os serviços ficaram sob a responsabilidade da Repartição de Águas e Esgotos (RAE), ligada ao governo do estado.

Mesmo diante de possíveis melhorias na oferta dos serviços de abastecimento de água ocorridos ao longo dos anos, a oferta continuou a não corresponder à demanda e, cada vez mais, uma peculiaridade se instaurou: a necessidade de se captar água em locais distantes para atender ao aumento da demanda.

\section{Entre a oferta e a demanda de água: dinâmicas e reformas}

Quando a Repartição de Água e Esgotos (RAE) assumiu os serviços de distribuição de água e coleta de esgotos, em 1892, eram duas adutoras fornecendo água para abastecimento da cidade: a do Ipiranga, que captava águas do córrego Ipiranga, represadas no atual Jardim Zoológico; e a da serra da Cantareira, que captava água nos mananciais localizados na serra. Em 1893, foi concluída a adutora do Guaraú, com o objetivo de conduzir água até o reservatório da Consolação. Um ano depois, captava-se água nos mananciais de Cassununga, Campo Redondo e Engordador que, reunidos numa caixa de junção denominada Guapira, aduziam águas para um reservatório no antigo Largo 13 de Maio, atualmente Praça Amadeu Amaral (THOMPSON, 1940: 32 e segs.; REVISTA LIGAÇÃO, 2000: 19 e segs.).

De 1895 a 1898, completaram-se as aduções dos recursos hídricos da serra da Cantareira, com a construção de um novo reservatório na Consolação, com capacidade de reserva de 19 milhões de litros. Em 1898, também se completou o aproveitamento das sobras do Engordador, na margem esquerda da Cantareira, e do Tanque Velho, no Ipiranga; além de iniciar a captação de água no rio Tietê, na altura do Belenzinho, cujas águas eram recalcadas para a zona baixa do Brás.

Quase uma década depois, após grande crise no abastecimento devido a uma estiagem, foi inaugurado, em 1907, o reservatório do Araçá, que aproveitava a canalização do reservatório Cantareira, com a adução 
das águas do Cabuçu e Barrocada. No ano seguinte, a Light and Power ${ }^{10}$ represou o rio Guarapiranga, na cabeceira do rio Pinheiros. A represa Santo Amaro, também chamada Guarapiranga, tinha na época capacidade para armazenar 196 milhões de metros cúbicos $\left(\mathrm{m}^{3}\right)$ de água.

Em 1914, uma epidemia de febre tifoide assolou a cidade, afetando a população de uma das regiões mais baixas, situada às margens do rio Tietê, que passou a sofrer com o consumo de suas águas já poluídas (SANTOS, 2011:205-206). Neste ano, iniciaram-se as obras para a adução das águas do rio Cotia, cuja primeira etapa previa a adução na cachoeira da Graça, como reforço para os bairros altos da cidade. $\mathrm{Na}$ segunda etapa, sucedida em 1920, foi construída a adutora Água Branca-Cotia. Com isso, a cidade passou a receber $156 \mathrm{mil} \mathrm{m}^{3}$ de água por dia. Ainda assim, a cidade continuava sujeita às oscilações de fornecimento em razão das estiagens e da baixa oferta. Esse sistema de captação distancia-se em 41 quilômetros $(\mathrm{km})$ do centro de São Paulo.

Associada à carência na oferta, também estava o problema da má qualidade da água servida à população. Tal fato foi o argumento utilizado pelo Guaraná Espumante, em uma peça publicitária de 1921, publicada no Jornal O Estado de S. Paulo, a qual trazia uma representação do diretor da Repartição de Águas e Esgoto e de vários moradores da cidade, de diferentes condições socioeconômicas (perceptíveis pelas roupas e adereços que utilizam), e em cujo diálogo o diretor sugeria aos reclamantes que deveriam substituir a água pelo refrigerante: "Doutor, está aqui uma amostra da agua que somos obrigados a beber... Santo Deus, para quem devemos appellar?", ao que responde o diretor:"Façam como eu... appellem para o Guaraná Espumante".

No ano seguinte a prefeitura decretaria a Lei $\mathrm{n}^{\circ} 2.543$, de 4 de outubro de 1922, que determinava que as águas servidas em hotéis, casas de pasto e botequins fossem todas filtradas, de acordo com as especificações de filtros e qualidade aprovados pelas autoridades competentes (SANTOS, 2011:210).

10 A São Paulo Light, Tramway \& Power Ltd. instalou-se em São Paulo em 1899, formada por capitais ingleses e norte-americanos com o objetivo de prestar serviços de transportes urbanos, mas logo passou a atuar em setores estratégicos que envolviam a urbanização, como a geração e a distribuição de energia elétrica, resultando no seu envolvimento em discussões e conflitos relativos ao uso da água (SANTOS, 2010: 5). 
Em 1925, "o clamor de falta dagua em São Paulo era enorme", aponta Thompson no artigo do boletim da RAE, que prossegue afirmando:

“...creou-se então a Comissão de Obras Novas, em 30-01-1926. Aproveitando os estudos iniciados em Março de 1925 pela Repartição de Aguas, para adução das águas do Rio Claro, a Comissão tomou a si a incumbência de estudar o plano geral de abastecimento de agua de São Paulo, para uma população de 2.300.000 habitantes" (THOMPSON, 1940: 33).

Assim, iniciaram-se as obras do sistema Rio Claro, afluente do Tietê localizado na Serra do Mar, cujo sistema poderia fornecer 6 metros cúbicos de água por segundo $\left(\mathrm{m}^{3} / \mathrm{s}\right)$. Mas em 1928, agravou-se a falta d'água, e a represa Guarapiranga passou a ser utilizada para abastecimento. A captação de água neste sistema distancia-se em $16 \mathrm{~km}$ do centro de São Paulo.

Por outro lado, a oferta dos serviços de abastecimento de água e coleta de esgotos esbarrava na expansão desordenada da cidade, que desde a segunda metade dos anos 1920 já assinalava padrões que se reproduziriam dali em diante: expansão horizontal, opções pelos ônibus e pelos automóveis, além de uma quase "total irregularidade perante as leis e códigos que determinavam o uso e ocupação do solo da cidade". Tais fatos se chocavam com o fato de a RAE necessitar que os loteamentos e as edificações fossem oficializados pela prefeitura para o seu atendimento, e, muitas vezes, isso não acontecia, dando margem a aberturas individuais de poços ao lado de fossas, por exemplo (ROLNIK, 2003: 165-166).

Com o Código de Águas, promulgado em 1934, o governo brasileiro previa a utilização prioritária dos rios e bacias hidrográficas para a geração de energia elétrica, o que acabou atendendo a interesses econômicos de grandes empresas, entre elas a Light (SANTOS, 2010). Esse caso revela como os interesses coletivos foram relegados a segundo plano ante aos interesses especulativos e às relações de poder instituídas, em especial desta empresa em São Paulo que, infelizmente, devido aos limites dessas páginas, não serão aqui discutidos ${ }^{11}$. De qualquer modo,

11 Sobre o poder político e econômico da Light na sua relação com a cidade de São Paulo, ver em especial SEABRA, 1987; SANTOS, 2011; CUSTÓDIO, 2012. 
três anos depois, outro reservatório foi concluído, o da Mooca, e, no ano seguinte, o sistema Rio Claro foi reformado e passou a fornecer 3,3 $\mathrm{m}^{3} / \mathrm{s}$. Este sistema está localizado a $82 \mathrm{~km}$ de São Paulo.

Em 1941, com uma população de mais de 1,3 milhão de habitantes, a água distribuída à população era originária da serra da Cantareira, Cabuçu, Cotia, Santo Amaro (Guarapiranga) e Rio Claro, totalizando quase 470 milhões de litros diários. Treze anos depois (1954), diante da expansão da cidade, a RAE foi extinta e suas funções incorporadas pelo Departamento de Águas e Esgotos (DAE), também sob a responsabilidade do governo do estado, que ficou encarregado da administração direta dos serviços de água e esgotos da Capital, de São Caetano do Sul, de Santo André, de São Bernardo do Campo e de Guarulhos, cidades vizinhas a São Paulo. Entre as principais alterações em sua estrutura estava a autonomia administrativa e financeira da então autarquia em que se transformara. Foi o início da reorganização do saneamento para a futura região metropolitana.

No âmbito econômico, após 1930, mudanças estruturais e antagonismos inter-regionais associados a questões políticas levaram Getúlio Vargas a empreender uma política de industrialização com redução dos poderes oligárquicos locais (em especial o paulista) que, combinado com uma legislação trabalhista direcionada às atividades citadinas dinamizaram ainda mais as grandes cidades. Tais fatores atraíram parcelas crescentes de trabalhadores às áreas urbanas, em especial para a cidade de São Paulo.

Os setores de bens de consumo cederam lugar à predominância de setores de bens de produção que, mesmo sendo uma tendência nacional, ganharam expressividade na cidade de São Paulo. As indústrias de material de transporte que respondiam por $5,9 \%$ da produção industrial da cidade em 1949 passaram a representar 16,5\% em 1959; ao passo que as cinco mais importantes empresas do setor de bens de consumo, em conjunto, tiverem queda no total da produção industrial paulistana de 47,3\%, em 1949, para 34,9\%, em 1959; enquanto as seis maiores indústrias do setor de bens de produção saltaram de uma participação de 34,9\%, em 1949, para 42,7\%, em 1959, segundo os dados do Censo de 1959 e 1960. Em decorrência, nas décadas de 1950-1960 a taxa de crescimento populacional chegou a 5,5\% ao ano (SINGER, 2004: 194-195).

Se, por um lado, o conjunto da dinamização econômica trazia aumento na demanda por serviços públicos, no plano político conflitos 
de ordem política frequentemente pautavam os representantes dos governos do estado e do município no que tange a obras e serviços públicos. Em 1955, por exemplo, num embate entre o prefeito, Juvenal Lino de Matos, e o governador Jânio da Silva Quadros, o primeiro acusou o segundo de desperdício de dinheiro público ao deixar materiais se deteriorando a céu aberto enquanto obras de ampliação do sistema de abastecimento de água permaneciam paralisadas. Em contrapartida, o governador, acuado, ameaçava processar o prefeito por crime contra a pessoa do governador em função de suas declarações. Enquanto isso, as obras continuavam sem execução e a falta d'água persistia (JORNAL O ESTADO DE S.PAULO, 01 DE SETEMBRO DE 1955: 11).

Em meio a uma nova crise de abastecimento em 1958 teve início a captação das águas do Rio Grande, localizado a $26 \mathrm{~km}$ do centro de São Paulo, na represa Billings ${ }^{12}$. Foi quando o governo estadual firmou novo convênio com a Light para a retirada de $9,5 \mathrm{~m}^{3} / \mathrm{s}$ de água da represa Guarapiranga (Santo Amaro). Esse objetivo só foi realmente alcançado na década de 1970. Até então, apenas $4 \mathrm{~m}^{3} / \mathrm{s}$ de água eram de fato retirados e tratados. E, em 1960, teve início a captação de água no Baixo Cotia, distante $36 \mathrm{~km}$ do centro de São Paulo.

Já nesta década, com espaços cada vez mais reduzidos devido a sua ocupação, a cidade já impunha certa nebulosidade quanto aos limites de seu território e dos municípios vizinhos, pois estavam:

12 A origem da Billings remonta a Asa White K. Billings, engenheiro da Light, que designou o também engenheiro F. S. Hyde, na segunda metade da década de 1920 para determinar um local para a construção de uma usina hidrelétrica; este sugeriu a inversão das águas do rio Grande - denominação do curso d'água do rio Pinheiros entre a nascente e a foz do Guarapiranga - para o rio das Pedras, que deságua no rio Cubatão, cuja topografia acidentada da região favoreceria a geração de energia, aproveitando uma queda em torno de 720 metros. Em seguida, a empresa adquiriu as terras necessárias às obras e, para complementar o projeto, a Light solicitou autorização para a construção das barragens no Alto Tietê, de modo a conduzir as águas dali provenientes para seus reservatórios no rio Grande (Billings). A Light obteve rapidamente as concessões necessárias dos órgãos públicos para sua execução, cuja perspectiva era gerar cerca de 1 milhão de $\mathrm{kW}$ quando concluída integralmente. Em 1927, foi formado o reservatório Billings por meio do represamento do rio Grande, interligando-o ao reservatório do rio das Pedras, o que promoveu um aumento na capacidade de armazenamento de água do sistema (SANTOS, 2011: 230 e segs.). 
imbricando-se umas nas outras e tornando os seus limites indistinguíveis. Nada diferencia São Paulo de Taboão da Serra e a separar esses dois municípios há apenas um córrego problemático e sujo, o córrego Pirajussara, que insiste em mostrar de maneira dramática a cada verão que roubamos espaços essenciais ao seu fluxo natural (FARIA, 2004: 56).

Neste mesmo período (meados do século XX), sob um contexto de expansão das atividades industriais que atraíam mão de obra para a cidade, os rios Tietê,Tamanduateí e Pinheiros já estavam bastante poluídos, e a represa Billings seguia o mesmo destino (JOR GE, 2007: 183). Segundo o Instituto Socioambiental, na década de 1970 a poluição das águas dos rios Tietê e Pinheiros já provocavam as primeiras florações de algas na Billings.

Segundo Singer (2004: 195-196), a partir de meados do século XX, com o desenvolvimento da indústria, elas atravessaram os limites da cidade de São Paulo e se instalaram nas cidades vizinhas, na Grande São Paulo (que anos depois fariam parte da RMSP). Tal processo coloca em relevo que, em 1959, 51\% do produto industrial do estado de São Paulo resultaram da indústria da capital; no entanto, ao se considerar a produção da Grande São Paulo neste mesmo ano, o total da produção em relação ao total do estado subia para 70\%. Esses números sugerem uma dinâmica urbana sistêmica nas cidades da região, e não somente na capital paulista que, evidentemente, trazia consigo um crescente aumento na demanda por serviços públicos, o que justificava a criação do DAE e a ampliação da sua área de atuação desde 1954, como já apontado.

E foi com o objetivo de dinamizar a execução e a qualidade dos serviços executados que em 1967 o DAE passou por uma reestruturação organizacional, com o objetivo de solucionar o persistente déficit nos serviços de abastecimento de água e de coleta e tratamento de esgotos. Com ela, criou-se a Companhia Metropolitana de Águas de São Paulo (Comasp) e a Companhia Metropolitana de Saneamento de São Paulo (Sanesp). Nessa reestruturação, coube ao DAE a operação do sistema distribuidor de água e de coleta dos esgotos do município de São Paulo, comprando a água da Comasp e distribuindo aos consumidores, e a coleta de seus esgotos, entregando-os à Sanesp para tratamento e disposição final.

A Comasp era uma empresa de capital misto, baseada numa sociedade de ações com a finalidade de captar, tratar e vender água potável 
no atacado a 37 municípios que constituem na atualidade a RMSP, inclusive, ao próprio DAE na capital paulista. Para isso deveria projetar, construir e operar todas as barragens, túneis, sistemas adutores metropolitanos etc. destinados a fornecer água potável até as redes distribuidoras das cidades. A opção fundava-se na lógica de que na "produção" as obras e os serviços exigiam soluções integradas; enquanto na distribuição, ao contrário, as administrações municipais poderiam melhor encadear as demandas e obras necessárias para o atendimento da população, que seriam realizadas de forma mais simples ${ }^{13}$.

No âmbito dessa reforma, e com as atribuições divididas entre a Comasp e a Sanesp, na cidade de São Paulo o DAE passou a denominar-se Superintendência de Água e Esgotos da Capital (SAEC) em 1970, com as funções de planejar, projetar, ampliar, manter e operar o sistema urbano de distribuição de água e coleta de esgotos. Em outras palavras, a superintendência gerenciava os recursos arrecadados através das tarifas decorrentes dos serviços prestados e pagava, com estes recursos, os serviços oferecidos pela Comasp e pela Sanesp.

Paralelo a essas alterações institucionais na gestão do saneamento em nível local, nacionalmente o governo militar instaurou uma política centralizadora para vários setores e, dentre eles, para políticas urbanas. Com elas, foram implementadas as diretrizes do setor de saneamento através do Sistema Financeiro de Saneamento (SFS), vinculado ao Banco Nacional de Habitação (BNH), e do Plano Nacional de Saneamento (Planasa), de 1971.

Com o Planasa, permitiu-se a utilização dos recursos do Fundo de Garantia por Tempo de Serviço (FGTS) e de fontes externas (como o Banco Mundial) para financiamento de obras que dessem conta de atingir o objetivo de oferecer, até 1980, serviços de abastecimento de

13 Já a Sanesp foi criada para executar e operar o sistema de afastamento, tratamento e disposição final dos esgotos na área que compreendia os municípios que constituem hoje a RMSP, com a função de solucionar e dar manutenção a obras de grande porte com equipes especializadas. Era uma empresa privada de capital misto, assim como a Comasp, que atuava mediante a realização de convênios com Prefeituras Municipais e com o DAE, responsável pelo saneamento da capital. Era de responsabilidade dos municípios as obras que interferiam diretamente sobre os usuários, enquanto à Sanesp cabiam as obras que garantiam o interesse coletivo comum a toda a Grande São Paulo (FUNDAÇÃO PATRIMÔNIO HISTÓRICO DA ENERGIA E SANEAMENTO, 2008: 20). 
água e coleta de esgotos para $80 \%$ e $50 \%$ da população urbana do país, respectivamente. É claro que a premissa adotada pelo Planasa refletiu a política centralizadora do período e procurou concentrar os serviços de água e esgoto por meio de economias de escala nas mãos de empresas estaduais, em detrimento da gestão municipal descentralizada. Essa prerrogativa deu origem às companhias estaduais de saneamento, as quais obtiveram a concessão dos serviços de saneamento de muitos municípios. Dentre elas, foi criada a Companhia de Saneamento Básico do Estado de São Paulo (Sabesp), em 1973 ${ }^{14}$.

Também sob a responsabilidade do governo do estado de São Paulo, a Sabesp foi constituída como uma empresa de capital misto que, em seu início, tinha suas atividades restritas à cidade de São Paulo, mas que nos anos seguintes expandiu sua atuação a vários municípios vizinhos e também para cidades do interior do estado. Foi a Sabesp, inclusive, que concluiu as obras do sistema Cantareira, em 1974, cuja construção iniciou-se sob o comando da Comasp, em 1967. Distante $79 \mathrm{~km}$ de São Paulo, o sistema Cantareira tinha capacidade de fornecer 4,5 mil litros de água por segundo.

Quanto ao Planasa, se aparentemente foi um avanço do ponto de vista do saneamento, ao colocar metas, estipular condições de financiamentos e estruturar organizacionalmente o atendimento dessas metas, por outro lado, também constituiu um problema:

priorizou as regiões e cidades mais ricas do país, o Sudeste e a RMSP e, dentro dela, as sub-regiões e bairros das classes médias e altas; priorizou o abastecimento de água e deixou em segundo plano a coleta e o tratamento de esgotos, desconsiderando o fato de que mais de $90 \%$ do volume de água potável inserida no sistema, sai poluída, após o uso doméstico, assim a poluição das águas urbanas aumentou desmesuradamente (CUSTÓDIO, 2012: 78).

Em 1982, com a poluição na Billings, por exemplo, foi construída a barragem Anchieta, separando o braço do Rio Grande do resto da re-

14 Em 1973 também foram criadas a Região Metropolitana de São Paulo (RMSP) e a Companhia Estadual de Tecnologia de Saneamento Ambiental (Cetesb). A Sabesp resultou da fusão da Comasp, Sanesp e SAEC, além da Companhia de Saneamento da Baixada Santista (SBS), da Companhia Regional de Água e Esgotos do Vale do Ribeira (Sanevale) e do Fomento Estadual do Saneamento Básico (Fesb). 
presa para garantir a qualidade da água e o abastecimento público. No ano seguinte, foi criado o Conselho Estadual do Meio Ambiente (Consema) e, em 1984, por conta da pressão de organizações ambientalistas, o governo estadual diminuiu a quantidade de água bombeada do rio Tietê para a Billings. Com isso, a partir de 1986, a Sabesp passou a executar o abastecimento metropolitano de água realizando a captação nos sistemas Cantareira, Guarapiranga, Rio Claro, Alto e Baixo Cotia e Ribeirão da Estiva.

Com a Constituição de 1988, a temática das águas tomou novas dimensões ao incorporar a descentralização administrativa aos serviços, com aspectos participativos e integrados à sua gestão, acrescida da titularidade dos serviços atribuída como direito aos municípios e a adoção da bacia hidrográfica como unidade de gestão. Também foram criados os conselhos de meio ambiente que estabeleceram normas, como a participação da sociedade civil, além da consolidação da legislação contra a poluição dos mananciais.

No início dos anos 1990 foi aprovada a Política Estadual de Recursos Hídricos do Estado de São Paulo, criado o Comitê da Bacia Hidrográfica do Alto Tietê (em cuja área localiza-se a RMSP) e, em 1992, entrou em operação o sistema de captação Alto Tietê, localizado a $36 \mathrm{~km}$ de São Paulo, formado por três reservatórios localizados no alto da Serra do Mar para captar água limpa voltada ao abastecimento da RMSP. Sete anos depois, teve início a elaboração do Programa de Recuperação Ambiental da sub-bacia hidrográfica da Billings/Guarapiranga.

Com esses sistemas, em 2009 a Sabesp possuía uma capacidade de captação, tratamento e distribuição de água à RMSP de $67,7 \mathrm{~m}^{3} / \mathrm{s}$, oriunda dos sistemas Cantareira $\left(33 \mathrm{~m}^{3} / \mathrm{s}\right)$, Billings/Guarapiranga (14 $\left.\mathrm{m}^{3} / \mathrm{s}\right)$, Alto Tietê $\left(10 \mathrm{~m}^{3} / \mathrm{s}\right)$, Rio Grande $\left(4,8 \mathrm{~m}^{3} / \mathrm{s}\right)$, Rio Claro $\left(4 \mathrm{~m}^{3} / \mathrm{s}\right)$, Alto Cotia $\left(1 \mathrm{~m}^{3} / \mathrm{s}\right)$, Baixo Cotia $\left(0,9 \mathrm{~m}^{3} / \mathrm{s}\right)$, os quais ainda não respondiam à demanda da população (RIBEIRO, 2011: 127) ${ }^{15}$.

15 Há ainda o sistema Ribeirão da Estiva, com capacidade de $0,1 \mathrm{~m}^{3} / \mathrm{s}$, localizado a 38 km de São Paulo. Esse sistema entrou em operação em 1973 (FUSP, 2009: 258). 
Figura 1 - Sistemas na Região Metropolitana de São Paulo

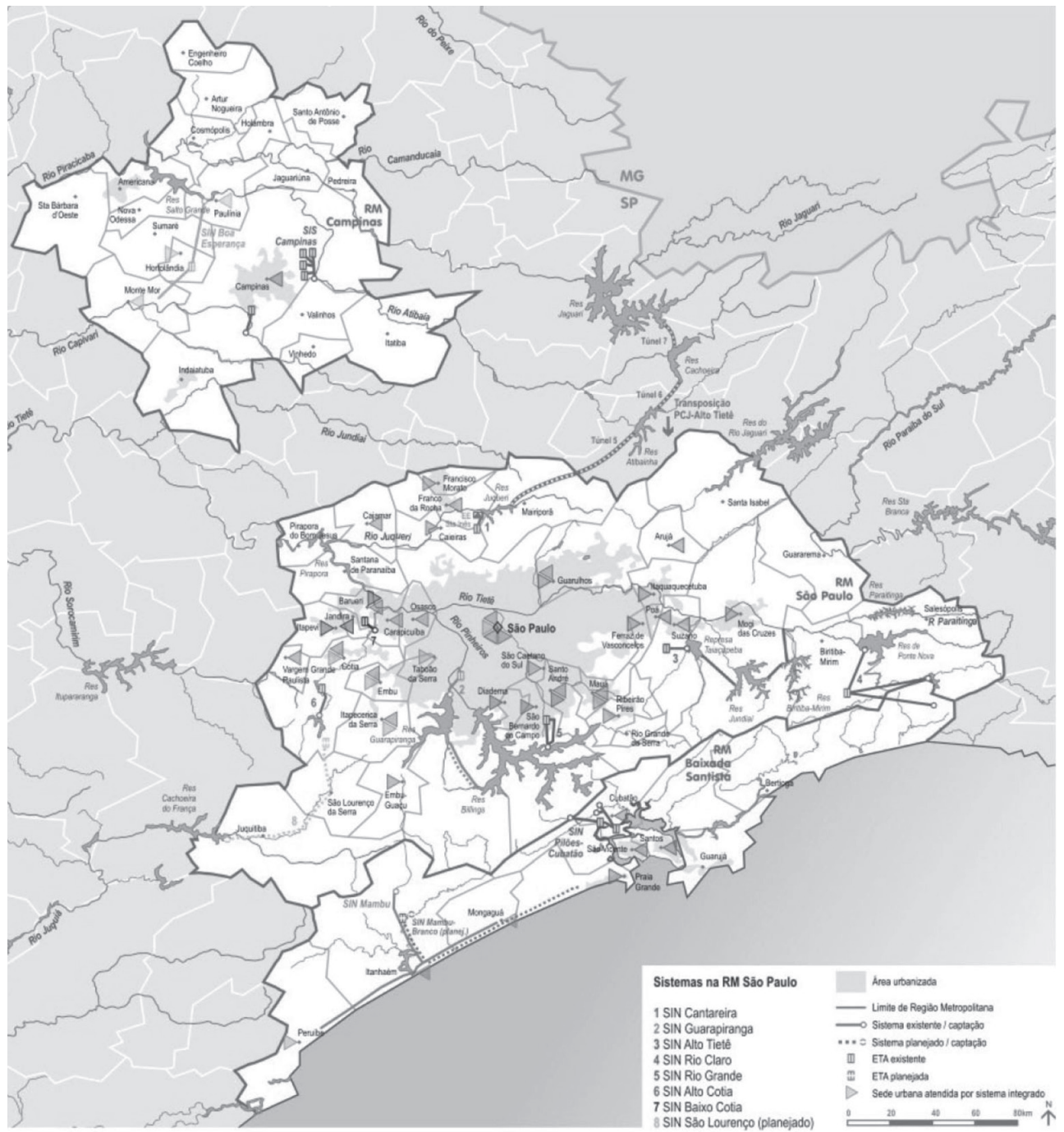

Fonte: (ANA, 2011).

Durante a década de 1990, a Sabesp passou por uma grande crise financeira que afetou diretamente sua capacidade de investimento, inclusive, para abastecimento da RMSP, além de relações conflituosas com 
os municípios (que lhes concederam os serviços de saneamento) e prejuízos, obrigando-a a uma reestruturação organizacional. Descentralizaram-se suas unidades de negócio em regiões com autonomia financeira em direta relação com as bacias hidrográficas. A lógica empresarial prevaleceu nas esferas de decisão, especialmente junto às prefeituras municipais, com o objetivo de recuperá-la financeiramente, aumentar o atendimento e estabelecer uma nova relação com os municípios. Em 1998, como resultado do novo modelo, os resultados financeiros já foram lucrativos (FUNDAÇÃO PATRIMÔNIO HISTÓRICO DA ENERGIA E SANEAMENTO, 2008: 24-25).

Se por um lado a Sabesp processou um "saneamento" nas suas intempéries financeiras e administrativas, por outro, o saneamento esperado e desejado, porque objeto fim da Companhia, não atingiu os mesmos objetivos. Este processo se revela ainda hoje sob inúmeras formas.

O volume de água captado no sistema Cantareira, por exemplo, que representa uma parcela significativa do total da água fornecida à população, assinala a peculiaridade da carência deste "saneamento", pois demonstra como a Sabesp é obrigada a buscar um significativo volume de água em outra bacia hidrográfica para abastecer a população ${ }^{16}$. Nesse caso, a água é oriunda da bacia do rio Piracicaba, situada ao norte da bacia do Alto Tietê, que ainda é complementada com águas advindas de reversões menores dos rios Capivari e Guaratuba.

Os números a seguir reafirmam a problemática ao demonstrar a projeção de demanda futura em relação à oferta em 2010 (considerando que a análise é de $2004^{17}$ ), permitindo vislumbrar um cenário futuro levando em conta uma projeção de população de 22,5 milhões de habitantes para a RMSP em 2025, tomando como base a situação do abastecimento atual e a possibilidade de integração de um novo sistema de captação. Os dados não são animadores, pois, mesmo considerando-se uma série de ações envolvendo o uso racional, o controle de perdas e o

\footnotetext{
16 Sobre a degradação das águas (rios) na cidade de São Paulo, ver em especial Seabra (1987); Pasqua (1998); Jorge (2006); Santos (2011).

17 A projeção de demanda, realizada pela Sabesp, em 2004, considerou um cenário tendencial, com predomínio das seguintes condições de fornecimento de água: i. manutenção da situação de perdas da época; ii. redução de $20 \%$ do consumo público e de $2 \%$ no residencial até o final do plano (uso racional); iii. aplicação de redutor decorrente de reuso e tarifa. (FUSP, 2008: 256).
} 
reuso da água, em ambos os casos apresentados (média e máxima para um cenário tendencial), mantém-se uma tendência de déficit de oferta em relação à demanda, ao tomar como base a capacidade de distribuição de $67,7 \mathrm{~m}^{3} / \mathrm{s}$ disponibilizada em 2010 , e até mesmo ao se considerar a adição de $4,7 \mathrm{~m}^{3} / \mathrm{s}$ a este total, como pretende o governo do estado de São Paulo e a Sabesp, com a inclusão do sistema São Lourenço, como será discutido adiante.

Tabela 1 - População da cidade de São Paulo, da Região Metropolitana de São Paulo e oferta e demanda hídrica - 1900-2025 (projeção)

\begin{tabular}{|c|c|c|c|c|c|c|}
\hline \multicolumn{2}{|c|}{ Cidade de São Paulo } & \multicolumn{5}{|c|}{ Região Metropolitana de São Paulo } \\
\hline \multirow[t]{2}{*}{ Ano } & \multirow[t]{2}{*}{ População } & \multirow[t]{2}{*}{ População } & \multirow[t]{2}{*}{ Ano } & \multirow[t]{2}{*}{$\begin{array}{c}\text { Oferta } \\
\text { (m3/segundo) }\end{array}$} & \multicolumn{2}{|c|}{$\begin{array}{c}\text { Demanda } \\
(\mathrm{m} 3 / \text { segundo })^{\star \star \star}\end{array}$} \\
\hline & & & & & Média & Máxima \\
\hline 1900 & $239.820^{\star}$ & - & 1894 & 0,3 & - & - \\
\hline 1910 & $375.439 \star$ & - & 1915 & 1,4 & - & - \\
\hline 1920 & $579.033^{\star}$ & - & 1929 & 2,7 & - & - \\
\hline 1930 & $887.810^{\star}$ & - & 1939 & 3,7 & - & - \\
\hline 1940 & $1.326 .261^{\star}$ & - & 1941 & 5,5 & - & - \\
\hline 1950 & $2.198 .096^{\star}$ & $2.653 .860 \star \star$ & 1958 & 8,2 & - & - \\
\hline 1960 & $3.781 .446^{\star}$ & $4.739 .406 \star \star$ & 1963 & 11,0 & - & - \\
\hline 1970 & 5.885 .475 & $8.139 .730 \star \star$ & 1975 & 20,7 & - & - \\
\hline 1980 & 8.475 .380 & $12.588 .725 \star \star$ & 1986 & 41,6 & - & - \\
\hline 1990 & 9.512 .545 & $15.444 .941 \star \star$ & 1996 & 59,7 & - & - \\
\hline 2000 & $10.434 .252^{\star \star}$ & $17.878 .703 \star \star$ & 2000 & $63,0 \bullet$ & 65,8 & 72,8 \\
\hline 2005 & - & - & - & - & 70,3 & 77,8 \\
\hline 2010 & $11.244 .369 \star \star$ & $19.683 .975^{\star \star}$ & 2009 & $67,7 \bullet$ & 75,0 & 83,0 \\
\hline 2015 & - & - & - & & 78,0 & 86,5 \\
\hline 2020 & - & - & - & & 80,9 & 89,9 \\
\hline 2025 & - & $22.500 .000 \star \star \star$ & 2025 & & 83,6 & 93,0 \\
\hline
\end{tabular}

Fontes: * SANTOS, 1994: 137.

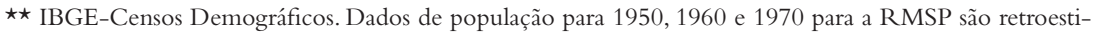
mativas recompostas as partir dos municípios da RMSP, elaborados pelo IBGE.

$\star \star \star$ FUSP, 2008;256-260. Dados elaborados pela Sabesp em 2004, a partir da demanda projetada para cenário tendencial considerando uma população de 22,5 milhões de habitantes em 2025 para a RMSP.

- RIBEIRO, 2004: 169.

- Ribeiro, 2011: 127.

Demais dados - Instituto Socioambiental.

O quadro acima reforça o processo no qual as “diferentes” empresas encarregadas pelo serviço de captação e abastecimento foram obrigadas ao longo dos anos a buscarem fontes de captação em regiões distantes, 
mesmo estando sobre uma relevante bacia hidrográfica. Tal fato simboliza a continuidade de um padrão que se reproduziu em meio às descontinuidades nas formas de gestão dos diferentes órgãos encarregados pela oferta de água desde o século XIX.

De qualquer forma, a reflexão não deve incorrer unicamente do ponto de vista da degradação da natureza, no caso das águas, mas também de processos que se interagem e garantem maior complexidade ao tema, como o contexto histórico, os interesses dos agentes envolvidos, as inovações tecnológicas etc. ${ }^{18}$. No caso da RMSP, em especial, ao longo dos anos a problemática das águas se deslocou de uma questão local e regional para um problema metropolitano e, em seguida, englobou outras regiões metropolitanas e outras bacias hidrográficas, avolumando ainda mais o problema ${ }^{19}$.

\section{Conflitos e negócios}

O problema que se coloca, portanto, é a possibilidade concreta de falta d'água na RMSP para o consumo humano primordialmente, que já é uma realidade, mas pode tornar-se crônica no futuro. Neste cenário de risco $^{20}$ de desabastecimento, acrescido do problema de desigualdade

18 Segundo Torrão Filho $(2007 ; 48-49)$, há que se atentar para o risco de se pensar a relação do homem com a natureza apenas do ponto de vista da destruição, visto que pode reforçar o dualismo entre natureza e sociedade, excluindo da análise outros fatores em torno do objeto.

19 As águas oriundas da bacia do Rio Piracicaba, que servem São Paulo, através do sistema Cantareira, também fornecem água para a Região Metropolitana de Campinas e cidades do estado de Minas Gerais; por isso, essa questão se tornou federal, e tem a mediação da Agência Nacional de Águas (ANA), agência reguladora nacional responsável pelo trato das águas no país.

20 A ideia de risco tem sua gênese na percepção de um perigo ou potencial ameaça que pode ter origens diversas, da mesma forma que é subjetiva e pode ser sentida por cada um, segundo a realidade e as condições socioeconômicas particulares. Ao ser percebida pelos indivíduos, "pode provocar, ao se manifestar, prejuízos às pessoas, aos bens e à organização do território. Pode-se, portanto, definir o risco como a representação de um perigo ou álea (reais ou supostos) que afetam os alvos e que constituem indicadores de vulnerabilidade" (VEYRET, 2007:30). Em outras palavras, se o risco é a percepção de que algo pode acontecer, só existe esta percepção se há elementos constitutivos para tal; e tais elementos são criados exatamente por aqueles que têm interesse pelo espaço, que nele interagem e o transformam. Da mesma 
social e econômica historicamente constituída, os conflitos podem resultar em situações desastrosas para toda a sociedade ${ }^{21}$.

Em 2011, por exemplo, por várias vezes funcionários da Sabesp foram feitos reféns por moradores do Jardim Papai Noel e do Cantinho do Céu, bairros do extremo sul da capital paulista, em razão da falta d'água. Os prejuízos se disseminaram por meio de escolas e postos de saúde, que foram fechados devido à falta d'água, além de ruas interditadas e pneus incendiados como resultado da mobilização dos moradores. No Jardim Papai Noel, a liberação do funcionário "aprisionado" aconteceu diante da "garantia" do fornecimento d'água à noite; no entanto, ela não durou nem um dia. No Cantinho do Céu, o funcionário foi cercado por um grupo de mulheres que declarou: "daqui você não sai enquanto a água não voltar”, relatou o funcionário sequestrado, que ficou 4 horas em poder dos moradores. Ele foi liberado após a chegada de um fiscal da Sabesp, que permaneceu em seu lugar até à noite.

Independentemente do procedimento adotado pela população como estratégia para o restabelecimento da água, é representativo destacar como o problema existe e atinge toda a sociedade, à medida que coloca o problema da desigualdade e do desequilíbrio social em relevo e abarca o problema do desabastecimento d'água, cujos custos sociais e econômicos são enormes, apesar de os custos imediatos sempre recaírem imediatamente sobre os excluídos dos direitos fundamentais à cidade, ou seja, dos equipamentos e serviços urbanos ${ }^{22}$. Ao mesmo tempo, porém, a Sabesp declara, segundo dados de dezembro de 2011, um "índice de atendimento urbano com abastecimento de água" de 100\% na RMSP, totalizando 15,9 milhões de habitantes em 38 municípios $^{23}$.

forma, Mary Douglas (1966) aponta que os riscos são frutos de uma construção cultural.

21 Segundo o Plano da Bacia do Alto Tietê (FUSP, 2009: 19), 58\% das outorgas para uso da água na RMSP destinam-se ao abastecimento público, seguido de $39 \%$ para consumo industrial, depois para uso sanitário (1\%), sanitário/industrial (1\%) e irrigação (1\%).

22 Entre outras estratégias adotadas, uma das moradoras do Jardim Papai Noel comprou uma piscina infantil, de plástico, no valor de $\mathrm{R} \$ 49,00$, para ser usada como reservatório de água (JORNAL O ESTADO DE S.PAULO, 2011: C12).

23 "Na Diretoria Metropolitana, a Sabesp atende 38 municípios sendo que 30 deles estão na Grande São Paulo e 8 na região de Bragança Paulista. A empresa também comercializa água por atacado a 6 cidades que são atendidas por serviços municipais". 
Diante dessa situação, que é representativa da condição de descasamento entre oferta e demanda e/ou das más condições de atendimento infraestruturais, no início de 2013 encontrava-se em fase de licitação outro sistema de captação de água para atender a RMSP, o sistema São Lourenço. Caso seja executado, as águas deste sistema serão captadas na Represa Cachoeira do França, região de Juquitiba, na bacia do Ribeira do Iguape, localizado a $74 \mathrm{~km}$ de São Paulo.

Além da distância, entre suas peculiaridades pesará a necessidade de bombear a água de uma elevação de 300 metros (equivalente a um prédio de 10 andares) para transpor a Serra de Paranapiacaba, o que deverá aumentar sobremaneira os custos da operação, estimada em R $\$ 500$ milhões/ano. Para efeito de comparação ambiental e econômica, a água captada pelo sistema Cantareira, elevada de um desnível de 100 metros por sua estação elevatória, consome, em um dia, energia elétrica suficiente para abastecer uma cidade como Bauru (JORNAL O ESTADO DE S.PAULO, 23 DE MARÇO DE 2012; C9; JORNAL O ESTADO DE S.PAULO, 09 DE NOVEMBRO 2012; C5), com 346 mil habitantes em 2011, segundo o IBGE.

O sistema está previsto para ser executado por meio da Parceria Público-Privada (PPP), na qual o concessionário privado terá a incumbência de construir e realizar a manutenção, enquanto à Sabesp caberá a operação do sistema. O edital de licitação foi publicado pelo governo do Estado de São Paulo e pela Sabesp em novembro de 2012, com custo de execução previsto em $\mathrm{R} \$ 1,68$ bilhão. A estimativa de receita à concessionária privada que vencer a licitação, pelos 25 anos de concessão, é de R \$ 6 bilhões (JORNALVALOR ECONÔMICO, 08 DE NOVEMBRO DE 2012). Entre as obras a serem construídas estão estações elevatórias, uma estação de tratamento, 78,3 km de adutoras, 4,9 km de adutoras auxiliares e reservatórios para armazenamento de 110 milhões de litros d'água bruta ou tratada (JORNAL O ESTADO DE S.PAULO, 09 DE NOVEMBRO DE 2012; C5). A previsão é que o novo sistema adicione $4,7 \mathrm{~m}^{3} / \mathrm{s}$ de água à capacidade de abastecimento da RMSP, o que significa água o suficiente para atender 1,5 milhão de habitantes nas cidades de Barueri, Carapicuíba, Cotia, Itapevi, Jandira, Santana de Parnaíba e

Sabesp. <http://site.sabesp.com.br/site/interna/Default.aspx?secaoId=4>. Acesso em 18 de junho de 2012. 
Vargem Grande Paulista. Ademais, o sistema também será interligado aos outros sistemas existentes na RMSP (SABESP; < http://site.sabesp. com.br/site/imprensa/noticias-detalhe. $\operatorname{aspx}$ ? secaold=66\&id=4711>. Acesso em 20 de fevereiro de 2012).

No cerne dessa discussão, cabe averiguar a magnitude da "carência" de água em relação a um panorama em que grande parte da RMSP se situa sobre uma importante e farta bacia hidrográfica, porém, sem condições de utilização de suas águas, colocando em perspectiva, portanto, questões que devem ser consideradas à luz desta realidade. Segundo Ribeiro, há que se avaliar a situação hídrica de uma região e a quantidade de água disponível por habitante por meio da aferição da sua escassez hídrica e/ou estresse hídrico. A escassez hídrica ocorre quando o volume de água é insuficiente para abastecer a população, devido, em geral, a baixos índices pluviométricos ou ao uso acima da oferta, ou ainda quando não há recursos financeiros disponíveis para captação e transporte da água da fonte até o consumidor; e o estresse hídrico é o "resultado da relação entre o total da água utilizada anualmente e a diferença entre a pluviosidade e a evaporação ocorrida na unidade territorial" (RIBEIRO, 2011). Em outras palavras, a escassez seria a efetiva falta de água numa dada região, enquanto o estresse seria uma pressão pela falta de água, sendo que, temporalmente, o segundo precede o primeiro fenômeno ${ }^{24}$. E, no caso de São Paulo e região metropolitana, a situação atual parece ser de estresse hídrico, entretanto, com claros indícios de que a situação de escassez pode não estar tão distante.

No caso da RMSP, segundo o próprio Ribeiro (2011: 125), os índices pluviométricos em torno de 1.400 milímetros (mm)/ano em média (dados de 2002) não permitem situar a região em situação de escassez hídrica, ao contrário, pois as chuvas, especialmente nas regiões da Serra do Mar são representativas, chegando a $3.000 \mathrm{~mm} /$ ano. Contudo, há uma especificidade peculiar a se considerar, que é a falta de condições de armazenamento da água em seus regimes de chuvas, para tratamen-

24 O próprio Ribeiro aponta que há um debate em torno dos critérios que definem uma situação de estresse hídrico, principalmente quando se discute o mínimo diário de água necessário a uma pessoa: se deve agregar ou não às necessidades vitais do homem a água "virtual", ou seja, aquela inclusa nos produtos industrializados consumidos por um indivíduo, o que aumentaria consideravelmente a água necessária à vida diária (RIBEIRO, 2008: 62 e segs.). 
to e posterior distribuição, o que acaba justificando a necessidade de se buscar água em mananciais distantes.

Acrescido a este fato, também há que se considerar o grande adensamento populacional que contribui sobremaneira para a reprodução de um padrão de contaminação dos mananciais e das águas que atravessam a RMSP, cujo processo encontra suas origens em séculos de intervenções do homem sobre a natureza. Esses fatores, em conjunto, explicam o fato de a região viver uma situação de estresse hídrico ${ }^{25}$, e de a Sabesp ter que importar um volume considerável de água da bacia do rio Piracicaba, por exemplo.

Segundo a avaliação do Atlas Abastecimento Urbano de Água (ANA, 2011), com exceção do Ribeirão da Estiva, todos os sistemas de captação de água da Sabesp, em 2010,já apontavam a necessidade de ampliações ou melhorias para assegurar o abastecimento de água para a RMSP até 2015, além da necessidade de implantação do sistema de captação São Lourenço. Essas obras, em seu conjunto, preveem investimentos no sistema de "produção de água", de acordo com o Atlas, de cerca de R $\$$ 4,07 bilhões, sem mencionar os investimentos requeridos para o sistema São Lourenço.

\section{Considerações finais}

Como apresentado, o fato de a RMSP se encontrar sobre a bacia hidrográfica do Alto Tietê não significa que ela está sobre águas disponíveis para utilização, e muito menos há uma correlação direta entre demanda e oferta hídrica, pois séculos de degradação das águas resulta-

25 Em termos globais, Ribeiro afirma que o crescimento demográfico não pode ser tomado como causa da crise de oferta d'água, pois a população mundial, de 1950 a 2000, dobrou em número, ao passo que o consumo d'água mais que quadruplicou neste mesmo universo. Portanto, sua análise recai sobre o consumo ter crescido de forma desproporcional à oferta de água, acrescida do fato de o sistema capitalista ter se apropriado da água como mercadoria; da degradação de mananciais e cursos d'água; da distribuição desigual no mundo; etc. (RIBEIRO, 2008: 53). Já Custódio (2012: 59-82), tratando especificamente da realidade da RMSP, afirma que a região vive uma situação de escassez hídrica devido à poluição; caso contrário, as águas da bacia do Alto Tietê seriam suficientes para abastecer toda a RMSP, pois sua vazão total é de $82 \mathrm{~m}^{3} / \mathrm{s}$, enquanto a demanda era de $67,7 \mathrm{~m}^{3} / \mathrm{s}$ em 2010 . 
ram em consequências calamitosas que se refletem cada vez com mais rigor, com custos ambientais, econômicos e sociais gritantes. Marcas indeléveis de um processo de ocupação urbana desigual e heterogênea de caráter privatista que instituiu suas diferenças sobre a cidade, as quais podem ser temas bastante interessantes para futuras pesquisas.

Não é em vão que a necessidade de obras, ampliações e novos sistemas de captação de água revelam a continuidade de um padrão historicamente constituído de execução de grandes obras sem o devido enfrentamento do real problema, ou seja, da "gestão" integrada dos múltiplos usos da água em consonância com sua urgente necessidade de tratamento dos resíduos gerados, sejam eles domésticos, industriais ou difusos ${ }^{26}$. Essa continuidade, por sua vez, é inversamente proporcional a uma série de descontinuidades - representada pelas reestruturações aplicadas nos órgãos responsáveis pelo fornecimento de água na cidade de São Paulo e depois para a RMSP, as quais foram empreendidas pelo governo do estado desde fins do século XIX.

$\mathrm{Na}$ confluência das continuidades com as descontinuidades estão as dinâmicas de uma estrutura produtiva que acaba por expor contradições deste mesmo processo e faz emergir interesses econômicos e conflitos. No caso da empresa atualmente responsável pelo fornecimento de água à população, enquanto gerencia seus papéis na Bolsa de Valores, Mercadorias e Futuros (BM\&FBovespa) e na New York Stock Exchange (Nyse) para atender continuamente aos interesses do mercado de capitais,

26 O governo do estado de São Paulo e a Sabesp executam, desde 1992, o Projeto Tietê, com o objetivo de universalizar a coleta e o tratamento de esgotos na grande São Paulo até 2020 e, consequentemente, despoluir o rio Tietê. Desde então, foram gastos R \$3,2 bilhões, segundo a Sabesp, o que elevou o número de estações de tratamento de esgotos de 2 para 5 e fez crescer o volume de tratamento, que passou de $26 \%$ para quase 70\% em 2008 (JORNAL O ESTADO DE S.PAULO, 22 DE SETEMBRO DE 2012; X3). Entretanto, em outubro de 2012, o Ministério Público do Estado de São Paulo ingressou na justiça contra a Sabesp, o governo do Estado, a Prefeitura Municipal de São Paulo e o Banco Interamericano de Desenvolvimento (BID) pedindo uma indenização de $\mathrm{R} \$ 11,5$ bilhões por danos causados por despejos de esgotos in natura nos rios e represas da RMSP, com o intuito de indenizar prejuízos ao meio ambiente e ao patrimônio público. Sobre a ação, que ainda tramitava na justiça em inícios de 2013, a Sabesp declarou que tal medida era um "desserviço" ao projeto que ainda estava em execução. De maneira análoga, outros municípios no interior do estado de São Paulo também processavam a Sabesp por danos ambientais em razão da falta de tratamento de esgotos (JORNAL O ESTADO DE S.PAULO, 12 DE OUTUBRO DE 2012; C4). 
também tem que lidar com conflitos em função da carência de água na cidade de São Paulo.

Nesse sentido, vale questionar até que ponto a poluição e a degradação das águas não interessariam e serviriam como justificativa para a manutenção do padrão estabelecido de grandes obras e em que medida a carência de coleta e de tratamento de esgotos não serviriam como condicionamentos úteis para a "geração" contínua de novos negócios em torno da água, de continuidade de um padrão, enquanto a empresa se adapta a novos negócios ${ }^{27}$. No outro lado da mesma moeda, não obstante, se observa que os conflitos em torno da água ainda corroboram desigualdades sociais.

Como indica Ricardo Abramovay (2010), no conjunto de uma sociedade em que pouco ou quase nada se discute sobre o que se deseja para o futuro e o que se pensa sobre desenvolvimento sustentável ${ }^{28}$, o resultado só poderia vir a ser a reprodução do descasamento entre a questão ambiental e o desafio de formular uma real política de desenvolvimento (sustentável), de modo a amenizar a pobreza. E, no caso aqui em discussão, pode-se pensar em um de seus inúmeros reflexos: o problema da oferta de água na RMSP.

O desafio é formular caminhos e estratégias para solucionar problemas imediatos, porém, com olhos no longo prazo para toda a sociedade, e claro, também considerando os investidores da Sabesp, de modo a se pensar na urgência de agir conjuntamente em prol de políticas públicas

27 Desde 2008 a Sabesp está autorizada, segundo a Lei Complementar Estadual n. ${ }^{\circ}$ 1.025, a desenvolver atividades no Brasil e no exterior. Com isso, além de expandir sua atuação geográfica, também ampliou o escopo de seus serviços relacionados à tecnologia ambiental, energia, drenagem, serviços de limpeza urbana e manejo de resíduos sólidos. Sabesp. <http://www.sabesp.com.br/CalandraWeb/CalandraRed irect $/$ ?temp $=4 \&$ proj=investidoresnovo $\&$ pub $=\mathrm{T} \& \mathrm{db}=\& \mathrm{docid}=124 \mathrm{CE} 9965 \mathrm{E} 00 \mathrm{~F} 49$ 7832576BD00604D3A\&docidPai=1698C08F24239E5A8325768C00517EF8\&pai= filho1> Acesso em 25 de junho de 2012.

28 Considerando como um processo de ampliação permanente das liberdades individuais em condições que lhes proporcionem a manutenção e a regeneração dos serviços prestados pelos ecossistemas às sociedades humanas. "Ele é formado por uma infinidade de fatores determinantes, mas cujo andamento depende, justamente, da presença de um horizonte estratégico entre seus protagonistas decisivos. O que está em jogo nesse processo é o conteúdo da própria cooperação humana e a maneira como, no âmbito dessa cooperação, as sociedades optam por usar os ecossistemas de que dependem" (ABRAMOVAY, 2010: 97). 
que deem conta de convergir às obras necessárias de ampliação dos sistemas de captação (aparentemente inevitáveis), despoluição, tratamento de resíduos etc. com programas de educação e cidadania de forma democrática que possibilitem a implantação de formas de gestão eficazes dos recursos naturais, com vistas à sustentabilidade no sentido mais amplo que o termo possa abarcar: em seus aspectos econômicos, sociais, políticos, culturais e ambientais.

Em outras palavras, o desafio é promover uma reinvenção da natureza que se deseja ou, no seu limite, de que se necessita, como resultado da intersecção de interesses de diferentes agentes e bacias envolvidas na negociação sobre a utilização das águas. Caso contrário, os custos econômicos, sociais e ambientais só tenderão a se elevar e seus efeitos deverão ser drásticos para toda a sociedade, ainda que os mais prejudicados social e economicamente já estejam sentindo os efeitos deste processo.

\section{Referências bibliográficas}

ABRAMOVAY, Ricardo. "Desenvolvimento sustentável: qual a estratégia para o Brasil?" In: Novos Estudos Cebrap. São Paulo: nº 87, Julho, 2010.

Agência Nacional de Águas (ANA). Atlas Abastecimento Urbano de Água. Brasília:Agência Nacional de Águas (ANA), 2011. Disponível em: < http://atlas.ana.gov.br/Atlas/ forms/analise/RegiaoMetropolitana.aspx?rme=24>. Acesso em 4 de abril de 2012.

BERMAN, Marshall. Tudo o que é sólido desmancha no ar. A aventura da modernidade. Trad., São Paulo: Cia. das Letras, 1986.

BRUNO, Ernani da Silva. História e tradições da cidade de São Paulo. São Paulo: Hucitec, 1991, vol. 3 .

CANO, Wilson. Raízes da concentração industrial em São Paulo. 4.ed., Campinas: I.E./ Unicamp, 1998.

COSTA, Wilma Peres. "A questão fiscal na transformação republicana - continuidade e descontinuidade.” In: Economia e Sociedade. Campinas: nº 10, jun. de 1998.

. "Economia primário-exportadora e padrões de construção do Estado na Argentina e no Brasil.” In: Economia e Sociedade. Campinas: nº 14, jun. de 2000.

CUSTÓDIO,Vanderli. Escassez de água e inundações na Região Metropolitana de São Paulo. São Paulo: Humanitas/ Fapesp, 2012.

DOUGLAS, Mary. Pureza e perigo. Ensaio sobre as noções de polvição e tabu. Trad., Lisboa: Edições 70, 1966.

ELIAS, Norbert. O processo civilizador. Uma história dos costumes. Trad., Rio de Janeiro: Jorge Zahar, 1994, vol. I. 
FARIA, Antonio A. da Costa. "Abastecimento de água na cidade de São Paulo (15541960). In: Revista do Arquivo Municipal. São Paulo: Departamento do Patrimônio Histórico, vol. 203, 2004.

Fundação de Apoio à Universidade de São Paulo (FUSP). Plano da Bacia Hidrográfica do Alto Tietê. São Paulo: Fundação de Apoio à Universidade de São Paulo, 2009.

Fundação Patrimônio Histórico da Energia e Saneamento. Empresas de Saneamento em São Paulo. São Paulo: Fundação Patrimônio Histórico da Energia e Saneamento, 2008.

HOLLOWAY,Thomas H. Imigrantes para o café. Café e sociedade em São Paulo, 1886-1934. Trad., Rio de Janeiro: Paz e Terra, 1984.

Infocidade<http://infocidade.prefeitura.sp.gov.br/htmls/7_populacao_recenseada_1950_699.html>.Acesso em 08 de junho de 2012.

Instituto Brasileiro de Geografia e Estatística (IBGE). Dados de população. Disponível em: <http://www.ibge.gov.br/home/presidencia/noticias/noticia_visualiza. php?id_noticia $=1766>$. Acesso em 4 de abril de 2012.

Instituto Socioambiental. Disponível em: < http://www.socioambiental.org/esp/agua/ pgn/grafico.htm\#>. Acesso em 4 de abril de 2012.

JORGE, Janes. Tietê, o rio que a cidade perdeu. OTietê em São Paulo, 1890-1940. São Paulo: Alameda/ Fapesp, 2006.

“À procura de um reencontro: o Tietê e os moradores de São Paulo.” In: MARTINEZ, Paulo Henrique (Org.). História ambiental paulista. Temas, fontes, métodos. São Paulo: Senac, 2007.

Jornal O Estado de S. Paulo: 01 de setembro de 1955; 20 de março de 2011; 23 de março de 2012; 22 de setembro de 2012; 12 de outubro de 2012; 09 de novembro de 2012 .

Jornal Valor Econômico. 8 de novembro de 2012.

MARTINEZ, Paulo Henrique. "O abastecimento de água: vida cotidiana e desigualdade social." In: . História ambiental paulista. Temas, fontes, métodos. São Paulo: Senac, 2007.

. História ambiental no Brasil. Pesquisa e ensino. São Paulo: Cortez, 2006.

MARTINS, Antonio Egydio. São Paulo antigo, 1554-1900. São Paulo: Paz e Terra, 2003

MASSEI, Roberto. “Argila: a dificil relação com a natureza.” In: MARTINEZ, Paulo Henrique. (Org.). História ambiental paulista. Teorias, fontes, métodos. São Paulo: Senac, 2007.

MERHY, Emerson Elias. O capitalismo e a saúde pública: a emergência das práticas sanitárias no Estado de São Paulo. 2.ed., Campinas: Papirus, 1987.

NOZOE, Nelson Hideki. São Paulo: economia cafeeira e urbanização. Estudo da estrutura tributária e das atividades econômicas na capital paulista (1889-1933). São Paulo: IPE/ USP, 1984.

PASQUA, Suzana P. Mortalidade e população no processo de urbanização da cidade de São Paulo (1890-1920) - o caso do Brás. São Paulo: Dissertação de Mestrado, FFLCH, USP, 1998.

Revista Ligação. Sabesp, São Paulo, set./ out. 2000. 
RIBEIRO, Wagner C. "Gestão das águas metropolitanas”. In: CARLOS, Ana Fani A.; OLIVEIRA, Ariovaldo U. de (Orgs.). Geografias de São Paulo: a metrópole do século XXI. São Paulo: Contexto, 2004.

- Geografia política da água. São Paulo: Annablume, 2008.

. "Oferta e estresse hídrico na Região Metropolitana de São Paulo.” In: Estudos Avançados. São Paulo: vol. 25, n. 71, jan./ abr. 2011.

ROLNIK, Raquel. A cidade e a lei. Legislação, política urbana e territórios na cidade de São Paulo. 3.ed., São Paulo: Nobel/ Fapesp, 2003.

Sabesp. Atendimento - Região Metropolitana de São Paulo. <http://site.sabesp.com. br/site/interna/Default.aspx?secaold=4>. Acesso em 18 de junho de 2012.

Sabesp. Relações com investidores. <http://www.sabesp.com.br/CalandraWeb/Calan draRedirect $/$ temp $=4 \&$ proj $=$ investidoresnovo $\& \mathrm{pub}=\mathrm{T} \& \mathrm{db}=\& \mathrm{docid}=124 \mathrm{CE} 9965$ E00F497832576BD00604D3A\&docidPai=1698C08F24239E5A8325768C00517EF 8\&pai=filho1 $>$. Acesso em 25 de junho de 2012.

Sabesp. Licitação do Sistema São Lourenço. <http://site.sabesp.com.br/site/imprensa/ noticias-detalhe.aspx?secaoId=66\&id=4711>. Acesso em 10 de fevereiro de 2013.

SANT'ANNA, Denise B. de. "Vida e morte dos chafarizes na cidade de São Paulo." In: Revista do Arquivo Municipal. São Paulo:Depto. do Patrimônio Histórico, vol. 203, 2004.

SANT'ANNA, Denise B. de. Cidade das águas. Usos de rios, córregos, bicas e chafarizes em São Paulo (1822-1901). São Paulo: Senac, 2007.

SANTOS, Fábio Alexandre dos. Rio Claro: uma cidade em transformação, 1850-1906. São Paulo: Annablume/ Fapesp, 2002.

. Uma empresa, vários negócios. A atuação da Light na ocupação e valorização do solo urbano da cidade de São Paulo (1900-1929). In: Segundo Congreso Latinoamericano de Historia Económica (CLADHE-II). México:Anais do II Congreso Latinoamericano de Historia Económica. México:Asociación Mexicana de Historia Económica (AMHE), 2010.

. Domando Águas. Salubridade e ocupação do espaço na cidade de São Paulo, $1875-$ 1930. Alameda/ Fapesp, São Paulo: 2011.

SANTOS, Milton. A urbanização brasileira. 2.ed., São Paulo: Hucitec, 1994.

SEABRA, Odette C. de L. Os meandros dos rios nos meandros do poder. Tietê e Pinheiros: valorização das várzeas na cidade de São Paulo. São Paulo: Tese de Doutoramento, FFLCH, USP, 1987.

SINGER, Paul. Desenvolvimento econômico e evolução urbana: análise da evolução econômica de São Paulo, Blumenau, Porto alegre, Belo Horizonte e Recife. 2.ed., São Paulo: Ed. Nacional, 1977.

“"Desenvolvimento”. In: SZMRECSÁNYI, Tamás (Org.). História Econômica da cidade de São Paulo. São Paulo: Globo, 2004.

SUZIGAN, Wilson. Indústria brasileira. Origem e desenvolvimento. São Paulo: Brasiliense, 1986.

THOMPSON, Oswaldo B. "Dados sobre o abastecimento de agua de São Paulo." In: Boletim da RAE. São Paulo: nº 9, RAE, 1940. 
TORRÃO FILHO,Amilcar."A cidade como redenção: natureza e cultura nos Campos de Piratininga.” In: MARTINEZ, Paulo Henrique (Org.). História ambiental paulista. Temas, fontes, métodos. São Paulo: Senac, 2007.

VEYRET, Yvette. Os riscos. O homem como agressor e vítima do meio ambiente. Trad., São Paulo: Contexto, 2007.

WORSTEN, Donald. "Para fazer história ambiental.” In: Estudos Históricos. Rio de Janeiro: vol. 4, nº 8, 1991. 